\title{
The effects of pesticide mixtures on degradation of pendimethalin in soils
}

\author{
Maria K. Swarcewicz • Andrzej Gregorczyk
}

Received: 27 September 2010 / Accepted: 8 June 2011 /Published online: 29 June 2011

(C) The Author(s) 2011. This article is published with open access at Springerlink.com

\begin{abstract}
Most agronomic situations involve a sequence of herbicide, fungicide, and insecticide application. On the other hand, use of pesticidal combinations has become a standard practice in the production of many agricultural crops. One of the most important processes influencing the behavior of a pesticide in the environment is its degradation in soil. It is known that due to several pesticide applications in one vegetation season, the pesticide may be present in mixtures with other pesticides or xenobiotics in soil. This study examines the role which a mixture of chemicals plays in pesticide degradation. The influence of other pesticides on the rate of pendimethalin (PDM) degradation in soil was measured in controlled conditions. Mixtures of PDM with mancozeb or mancozeb and thiamethoxam significantly influenced the degradation of pendimethalin under controlled conditions. The second type of
\end{abstract}

M. K. Swarcewicz $(\square)$

Institute of Organic Chemical Technology,

Department of Organic Synthesis and Drug Technology,

West Pomeranian University of Technology,

Aleja Piastow 42,

71-065 Szczecin, Poland

e-mail: mswar@zut.edu.pl

A. Gregorczyk

Faculty of Environment Management and Agriculture,

Department of Agronomy,

West Pomeranian University of Technology,

Pawla VI 3,

71-459 Szczecin, Poland mixtures, with metribuzin or thiamethoxam, did not affect the behavior of pendimethalin in soil. Also, we determined the influence of water content on the rate of pendimethalin degradation alone in two soils and compared it to the rate in three pesticide mixtures. We compared two equations to evaluate the predictors of the rate of herbicide dissipation in soil: the first-order kinetic and the non-linear empirical models. We used the non-linear empirical model assuming that the degradation rate of a herbicide in soil is proportional to the difference of the observed concentration of herbicide in soil at time and concentration of herbicide in the last day of measurement.

Keywords Dissipation · Mancozeb · Metribuzin · Pendimethalin $\cdot$ Soil $\cdot$ Thiamethoxam

\section{Introduction}

In practice, pesticides are usually applied simultaneously or one after another for crop protection, and this type of pesticide application often leads to a combined contamination of pesticide residues in the soil environment. Many interactions are possible, including those related to changes in the size or species composition of the soil microbial population, effects upon specific enzymatic reactions, or those related to physiochemical effects such as competition for adsorption sites (Singh et al. 2002a). As of now, numerous publications exist pertaining to the inter- 
actions between pesticides and soil microorganisms as is the case with the in pesticide combinations. On the other hand, the role of pesticide mixtures or pesticide degradation products in exerting influence on the persistence of parent compounds can be significant. For example, studies with a mixture of isoproturon and chlorothanoil showed that interactions between pesticides are possible in soil (Fogg et al. 2003).

Pendimethalin [ $N$-(1-ethylpropyl)-2,6-dinitro-3,4xylidine] is a preemergence dinitroaniline herbicide, which is commonly used for selective weed control in cotton, soybeans, maize, wheat, rice, peas, and vegetable crops. Persistence of pendimethalin (PDM) is influenced by cultivation practices, soil temperature, and moisture conditions, as well as soil type (Smith et al. 1997; Lee et al. 2000; Stranberg and Scott-Fordsmand 2004). PDM is characterized by low water solubility, moderate to high vapor pressure, strong adsorption to soil, and high octanol-water partition coefficients. The movement of this herbicide in surface runoff and leaching is expected to be low except where soil erosion results in sediment transport of the adsorbed herbicide (Stranberg and ScottFordsmand 2004; Chopra et al. 2010). The US Environmental Protection Agency has classified this herbicide as persistent-bioaccumulative toxics (Roca et al. 2009). The dinitroaniline herbicides are subject to a variety of biotic and abiotic transformation processes (Jaźwa et al. 2009; Stranberg and ScottFordsmand 2004; Singh et al. 2002b).

The insecticide thiamethoxam (3-(2-chloro-thiazol5-yl methyl)-5-methyl-[1,3,5] oxadiazinan-4-ylidene$\mathrm{N}$-nitroamine) is a nitromethylene-derived neonicotinoid with contact, stomach, and systemic activity. Gupta et al. (2008) have conducted a laboratory study on the persistence of thiamethoxam a 90-day period. They have reported the half-life of 91-94 days under normal field capacity moisture regime. However, Karmakar et al. (2006) have reported half-life of 16.9 days. Though much work has been carried out on its bioefficacy as seed treatment or foliar spray, not much published information is available on its persistence and leaching behavior (Gupta et al. 2008).

Mancozeb [manganese ethylenebis(dithiocarbamate) (polymeric)complex with zinc salt] is an ethylene bisdithiocarbamate. In soil, mancozeb is metabolized to ethylene thiourea, ethylene urea, and ethylene bisisothiocyanate sulfide. The data concerning persistence of these substances in soil are not consistent and the reported values vary from 1 to 165 days (Rhodes 1977; Wauchope et al. 1992; Hanumantharaju and Awasthi 2004).

Metribuzin [4-amino-6-t-butyl-3-(methylthio)-1,2,4triazin-5 (4H)-one] is a selective systemic herbicide used for pre- and post-emergence control of many grasses and broad-leaved weeds in soya beans, potatoes, tomatoes, sugar cane, alfalfa, asparagus, maize, and cereals. Metribuzin belongs to the group of triazinone herbicides and moderates persistence in soils, the half-lives measurements have been specified between 5 and 50 days. The decomposition of metribuzin in the environment is due to microbiological and chemical processes (Locke and Harper 1991).

Quantification of the fate of pesticides in the environment is therefore essential, but apparently very difficult. The decline of residues is estimated by simple first-order kinetics but this model is not adequate to describe the degradation of PDM, therefore empirical non-linear equations or mechanistic models have been used to describe existing biphasic degradation patterns (Zimdahl and Gwynn 1977; Walker and Bond 1977; Zimdahl et al. 1984, 1994; Leake et al. 1995; Tsiropoulos and Miliadis 1998; Lee et al. 2000). Additionally, there have been attempts to describe the non-linear decline of herbicide residues in soil, including bi-exponential kinetics model and the hockey-stick model (FOCUS 2006). This study was designed to reevaluate previous work on pendimethalin assuming that other empirical equations might compensate for the observed deficiencies in the first-order model. Our proposition was to use the non-linear empirical model assuming that the degradation rate of a herbicide in soil is proportional to the difference between the observed concentration of herbicide in soil at time $(C)$ and concentration of herbicide in the last day of measurement $\left(C_{\mathrm{L}}\right)$. It is described by differential equation:

$\mathrm{d} C / \mathrm{d} t=-k\left(C-C_{L}\right)$

where $t$ is the time (days), $k$ is degradation rate constant (per day).

Integration of this differential rate equation yields:

$C(\mathrm{t})=\left(C_{0}-C_{L}\right) \cdot e^{-k t}+C_{\mathrm{L}}$

where $C(0)=C_{0}$ is the initial concentration, $C_{\mathrm{L}}$ is the residue of herbicide in soil in the last day of measurement. 
This function has a horizontal asymptote:

$\lim C(\mathrm{t})=C_{\mathrm{L}}$

$\mathrm{t} \rightarrow \infty$

For half-life $\left(\mathrm{DT}_{50}\right)$ for a herbicide, we have:

$\mathrm{DT}_{50}=\frac{1}{k} \ln \frac{2 \cdot\left(C_{0}-C_{L}\right)}{C_{0}-2 \cdot C_{L}} \quad C_{\mathrm{L}}<0.5 C_{0}$

where $C_{0}$ is the initial concentration (milligrams per kilogram of soil), $C_{\mathrm{L}}$ is the residue of herbicide in soil in the last day of measurement (milligrams per kilogram of soil), $k$ is the degradation rate constant (per day).

The main objective of this study was to provide a better understanding of the interaction mechanisms involved in degradation of PDM in soil considering various mixtures of pesticide in controlled conditions. This study compares residual concentration after application of pendimethalin (herbicide), mancozeb (fungicide), thiamethoxam (insecticide), and metribuzin (herbicide). This research also examines the role which a mixture of chemicals plays in pendimethalin degradation. The two incremental objectives for this study are: (1) to determine the rates of PDM in the various mixtures, type of soils, and soil moistures, (2) to compare two models: the first-order kinetic model and a new non-linear differential model (Eq. 1.1).

The choice of pendimethalin as a model herbicide was somewhat arbitrary, except that it has been widely used in Poland for many years. This herbicide is one of several preemergence herbicides available for controlling weeds that invade potato crops.

\section{Materials and methods}

Commercial formulations of pendimethalin (Stomp 330 EC, 330 ga.i. ${ }^{-1}$, BASF), mancozeb (Dithane NeoTec 75 WG, 75 ga.i. $\mathrm{kg}^{-1}$, Dow AgroSciences), thiamethoxam (Actara $25 \mathrm{WG}$ including 25 ga.i. $\mathrm{kg}^{-1}$, Syngenta Crop Protection), metribuzin (Sencor 70WG, 70 ga.i. $\mathrm{kg}^{-1}$, BayerCropScience $\mathrm{AG}$ ), and analytical grade of PDM were used throughout these studies.

Two soils were used for all studies. The first was a sandy loam from Lipnik with textural composition of $72 \%$ sand, $16 \%$ silt, and $12 \%$ clay. This soil had a $\mathrm{pH}$ of 6.4 , organic matter $1.7 \%$, and cation exchange capacity of $2.20 \mathrm{cmol} \mathrm{kg}^{-1}$. The second Ostoja soil was a clay loam with $40 \%$ sand, $34 \%$ silt, $26 \%$ clay, $1.5 \%$ organic matter, and a $\mathrm{pH}$ of 6.3 . Both soils are commonly used in agricultural production, and all soil characteristics presented describe the $0-$ to $10-\mathrm{cm}$ soil zone. The sandy loam and the clay loam were collected from upper layer of soil $(0-10 \mathrm{~cm})$, airdried and finally screened through a $3-\mathrm{mm}$ sieve.

Portions of soil $(450 \mathrm{~g})$ were treated with aqueous solution of PDM alone, and four mixtures: (1) pendimethalin and mancozeb; (2) pendimethalin and thiamethoxam; (3) pendimethalin and metribuzin; (4) pendimethalin, mancozeb, and thiamethoxam. Persistence of PDM in soil under laboratory condition was studied using PDM concentration of $2 \mathrm{mg} \mathrm{kg}^{-1}$ airdried soil, mancozeb at $2.1 \mathrm{mg} \mathrm{kg}^{-1}$, metribuzin at $2.0 \mathrm{mg} \mathrm{kg}{ }^{-1}$, thiamethoxam at $10 \mathrm{mg} \mathrm{kg}^{-1}$. The pesticide solutions were used to adjust the water content of the soil to $60 \%$ of field capacity.

In the second part of the study, soils were treated with aqueous solution of PDM alone, and three mixtures: (1) pendimethalin and mancozeb; (2) pendimethalin and thiamethoxam; (3) pendimethalin, mancozeb, and thiamethoxam under $30 \%$ and $90 \%$ of field capacity. We used the same concentrations of pesticides, as above. After mixing the soil, samples were transferred to jars and incubated at $22^{\circ} \mathrm{C} \pm 2{ }^{\circ} \mathrm{C}$. All treatments were replicated three times. The jars were opened once a week, for the sake of aeration and the water content was adjusted by weighing. Three 50 -g samples of each soil were taken for herbicide residue analysis $1 \mathrm{~h}$ after the initial mixing, and 2, 10, 15, 30, 45, 60, 90 days after treatment. All treatments were replicated three times. A $50-\mathrm{g}$ portion of each sample was taken for moisture measurement and 50-g soil samples were shaken for $1 \mathrm{~h}$ on a wrist-action shaker with $100 \mathrm{~mL}$ of acetone. After shaking, the soil was allowed to remain in contact with the extracting solvent for further $20 \mathrm{~h}$ before being shaken for another 1-h period. The extract was filtered through a Whatman no.2 filter paper in a Buchner funnel. After the final extraction, the soil was rinsed with several portions of acetone. To the acetone extract $25 \mathrm{~mL}$ distilled water and $75 \mathrm{~mL} n$-hexane were added in a separatory funnel and that was shaken to transfer the PDM into the hexane phase. The hexane layer was collected, and stored over anhydrous $\mathrm{Na}_{2} \mathrm{SO}_{4}$. The extract was evaporated to obtain $2 \mathrm{~mL}$ and cleaned on a Florisil column, gas chromatography on Carlo Erba-Vega 6180 as capillary. 
Recoveries for soil fortified at the $2 \mathrm{mg} \mathrm{kg}^{-1}$ level were $98 \% \pm 4 \%$ for PDM (Swarcewicz 2002).

Data on soil degradation of PDM were subjected to one-way analysis of variance. Homogeneous groups were formed on the base of multiple range Tukey's test. All statistical hypotheses were verified at the significant level 0.05 . Plots of models predicting curves were obtained with the non-linear regression procedures, available with Statistica package. Values of the estimated parameters in Eq. 1.1 and the first-order reaction were found using the Lavenberg-Marquardt method. As a measure of approximation for accuracy of theoretical curves in relation to experimental data we accepted the determination coefficient $\left(R^{2}\right)$, which can be calculated as a square of the correlation coefficient between the observed and estimated values.

\section{Results and discussion}

Effect of pesticide mixtures

In the present study, measurements of the residual pendimethalin (PDM) concentration in four pesticide mixtures were compared with disappearance of this herbicide alone in the two soils under various soil moisture. The values of $\mathrm{DT}_{50}$ increased from 26.9 to 62.2 days in sandy loam (Table 1) and from 44.4 to 63.3 days, when PDM was alone and in mixture with mancozeb and thiamethoxam in clay loam at $60 \%$ of field capacity, using Eq. 1.4. The dissipation curves

Table 1 Influence of the presence of other pesticides on dissipation of pendimethalin in soil at $60 \%$ of field capacity and incubated at $22^{\circ} \mathrm{C} \pm 2^{\circ} \mathrm{C}$

\begin{tabular}{lcc}
\hline Treatment & \multicolumn{2}{l}{$\begin{array}{l}\text { Half-life of pendimethalin } \\
\text { in soil (days) }\end{array}$} \\
\cline { 2 - 3 } & Sandy loam & Clay loam \\
\hline Pendimethalin alone & $26.9 \mathrm{a}^{*}$ & $44.4 \mathrm{a}$ \\
Pendimethalin+thiametoxam & $35.6 \mathrm{ab}$ & $54.4 \mathrm{ab}$ \\
Pendimethalin+metribuzin & $28.7 \mathrm{a}$ & $37.7 \mathrm{ab}$ \\
Pendimethalin+mancozeb & $46.1 \mathrm{~b}$ & $63.9 \mathrm{~b}$ \\
Pendimethalin+thiametoxam+ & $62.2 \mathrm{c}$ & $63.3 \mathrm{~b}$ \\
mancozeb & & \\
\hline
\end{tabular}

$\mathrm{a}, \mathrm{b}, \mathrm{c}$ - means in the column marked by the same letters they do not differ significantly

${ }^{*} p=0.05$; level of significance (Tukey test) for PDM had the initial rapid rate of loss and were slower after 30 days (Fig. 1). Presence of mancozeb in both soils can also significantly influence the rate of disappearance of PDM (DT 5046.1 and 63.9 days, respectively). No significant effect was noticed when the substance in soils was thiametoxam (Table 1). Presence of metribuzin in soil did not affect the behavior of PDM in soil. In most agronomic situations, any single herbicide treatment is frequently a small part of the overall crop protection program. This often involves a sequence of herbicide, fungicide, and insecticide applications. There is not much information available about the behavior of multiple applications of either individual or combinations of pesticides. Many interactions are possible, including those related to changes in the size or species composition of the soil microbial population (Hurle and Walker 1980) to effects on specific enzymatic reactions (Kaufman and Edwards 1982), or to physicochemical effects such as competition for adsorption sites. PDM is known to be strongly adsorbed by soil and organic matter, possibly due to its high potential for hydrogen bonding (Weber 1990), resulting in a decrease of mobility and bioavailability of this compound. The clay content of soil may be also important in determining a herbicide persistence. Analysis of PDM variance residues in soil in controlled conditions showed a significant difference between soil types. The degradation rates of PDM in soil in presence of other pesticides also decreased as clay content increased, presumably because of increased adsorption, hence a decreased availability for degradation in heavier soil. A mixture of PDM, thiamethoxam, and mancozeb significantly inhibited the rate of degradation of PDM (Table 1). Similar observations have been reported for PDM and mancozeb in pot and field experiments in our early study (Swarcewicz 2002). Study of Wybieralski et al. (2000) and Swarcewicz et al. (2003) showed that mancozeb and its mixture with the insecticides bromfenvinphos, diazinon, and metribuzin affected the respiration and nitrification processes in a loamy sand. This suggested that mancozeb could influence the biodegradation of PDM in soil, too. The effect of different herbicides, fungicides, and insecticides on the degradation of PDM in the soil was investigated by Plieth and Börner (1985). The results showed that in presence of mecoprop salt, triadimefon, thiophanate methyl, bromophos, and oxydementon methyl did not influence the decomposition of PDM in field conditions. The 
Fig. 1 Dissipation of pendimethalin alone and in mixture with mancozeb and thiametoxam in soils under $60 \%$ of field capacity, using the differential model. Symbols are average of three replications, and bars represent $95 \%$ confidence intervals. Black square pendimethalin alone; white square pendimethalin plus mancozeb plus thiamethoxam

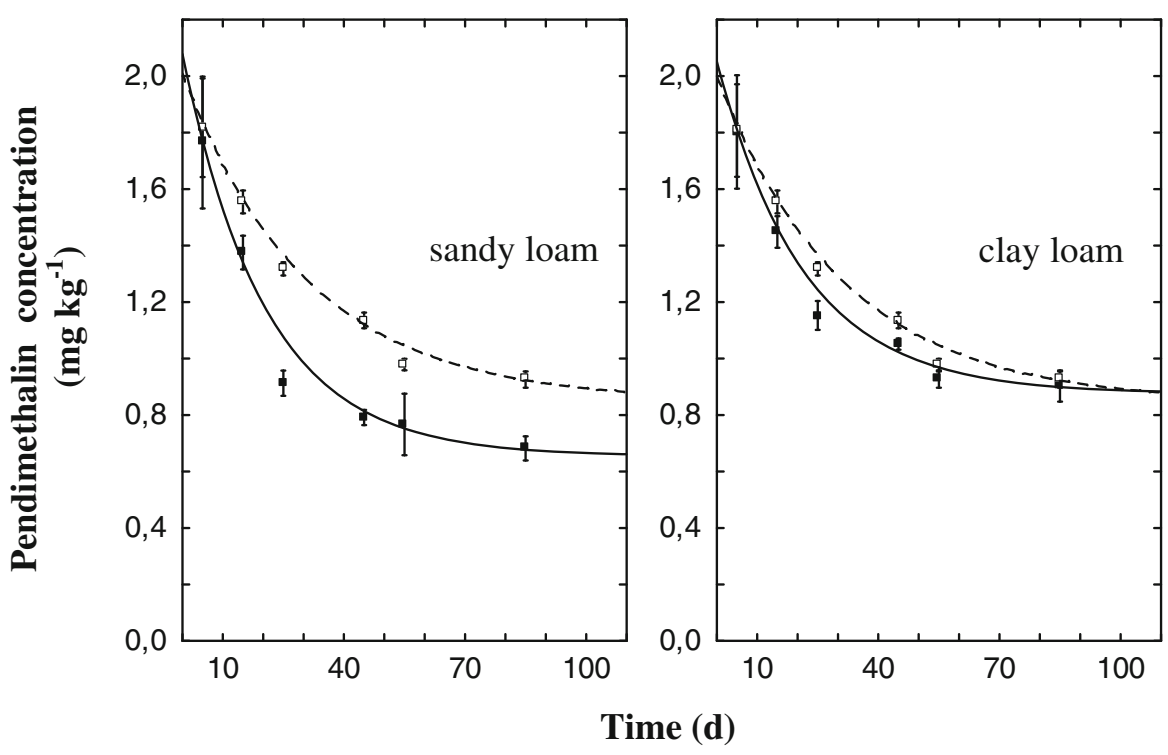

loss of both triallate and trifluralin from the plots treated with the mixture was the same as from plots treated with the individual compounds (Smith 1979). This result is in contrast with a study regarding the other pesticides. Kaufman (1966) showed that dalapon is more persistent in soil when applied in combinations with amitrole. This increased persistence was probably affected through the inhibition of dalapon-decomposing microorganism by amitrole. The same effect showed Fogg et al. (2003) for isoproturon $\mathrm{DT}_{50}$ values increased from 18.5 to 71.5 days in the presence of chlorothalonil in topsoil. The preplant fumigant Vorlex can induce destruction of soil fungi resulting in an increasing persistence of linuron (Smith 1982). From the few studies reported, it may be concluded that the breakdown of major herbicides is not being significantly affected by application in combination with other herbicides. It was confirmed in this study. This may not be true when herbicides are applied to soils receiving treatments of fungicides and insecticides which tend to appear more toxic to soil microorganisms than herbicides, and clearly more research in this area would be desirable. In this study, mancozeb as a fungicide has more significantly affected the persistence of PDM than insecticide thiamethoxam.

\section{Effect of soil moisture}

Dissipation of PDM proceeds more rapidly under flooded, anerobic conditions than cold or dry conditions

Table 2 Influence of the presence of other pesticides on dissipation of pendimethalin in three soil moisture contents in the laboratory and incubated at $22^{\circ} \mathrm{C} \pm 2{ }^{\circ} \mathrm{C}$

\begin{tabular}{|c|c|c|c|c|c|c|c|c|}
\hline \multirow{3}{*}{$\begin{array}{l}\text { Water content } \\
(\% \text { of field capacity) }\end{array}$} & \multicolumn{8}{|c|}{ Half-life of pendimethalin in soil (days) } \\
\hline & \multicolumn{4}{|c|}{ Sandy loam } & \multicolumn{4}{|c|}{ Clay loam } \\
\hline & $\mathrm{P}^{*}$ & $\mathrm{P}+\mathrm{T}$ & $\mathrm{P}+\mathrm{D}$ & $\mathrm{P}+\mathrm{T}+\mathrm{D}$ & $\mathrm{P}$ & $\mathrm{P}+\mathrm{T}$ & $\mathrm{P}+\mathrm{D}$ & $\mathrm{P}+\mathrm{T}+\mathrm{D}$ \\
\hline 30 & $94.6 \mathrm{a}^{*}$ & $80.0 \mathrm{a}$ & $77.4 \mathrm{a}$ & $121.8 \mathrm{a}$ & $112.7 \mathrm{a}$ & $118.4 \mathrm{a}$ & $134.5 \mathrm{a}$ & 150.9 a \\
\hline 60 & $26.9 \mathrm{~b}$ & $35.6 \mathrm{~b}$ & $46.1 \mathrm{~b}$ & $62.2 \mathrm{~b}$ & $44.4 \mathrm{~b}$ & $54.4 \mathrm{~b}$ & $63.9 \mathrm{~b}$ & $63.3 \mathrm{~b}$ \\
\hline 90 & $21.9 \mathrm{~b}$ & $24.4 \mathrm{c}$ & $34.2 \mathrm{c}$ & $33.5 \mathrm{c}$ & $27.9 \mathrm{c}$ & $29.7 \mathrm{c}$ & $55.2 \mathrm{bc}$ & $65.7 \mathrm{~b}$ \\
\hline
\end{tabular}

Mixture: $P$ pendimethalin alone, $P+T$ pendimethalin plus thiametoxam, $P+D$ pendimethalin plus mancozeb, $P+T+D$ pendimethalin plus thiametoxam plus mancozeb

$\mathrm{a}, \mathrm{b}, \mathrm{c}$ - means in the column marked by the same letters they do not differ

${ }^{*} p=0.05$; level of significance (Tukey test) 
Fig. 2 Comparison of pendimethalin dissipation alone and in the presence of mancozeb in soils under two moisture levels $(30 \%$ and $90 \% \mathrm{fc}$ ), using the differential model. Symbols are average of three replications, and bars represent $95 \%$ confidence intervals. black square pendimethalin alone at $30 \%$ fc; black triangle pendimethalin alone at $90 \%$ fc; white square pendimethalin plus mancozeb at $30 \% \mathrm{fc}$; white triangle pendimethalin plus mancozeb at $90 \% \mathrm{fc}$
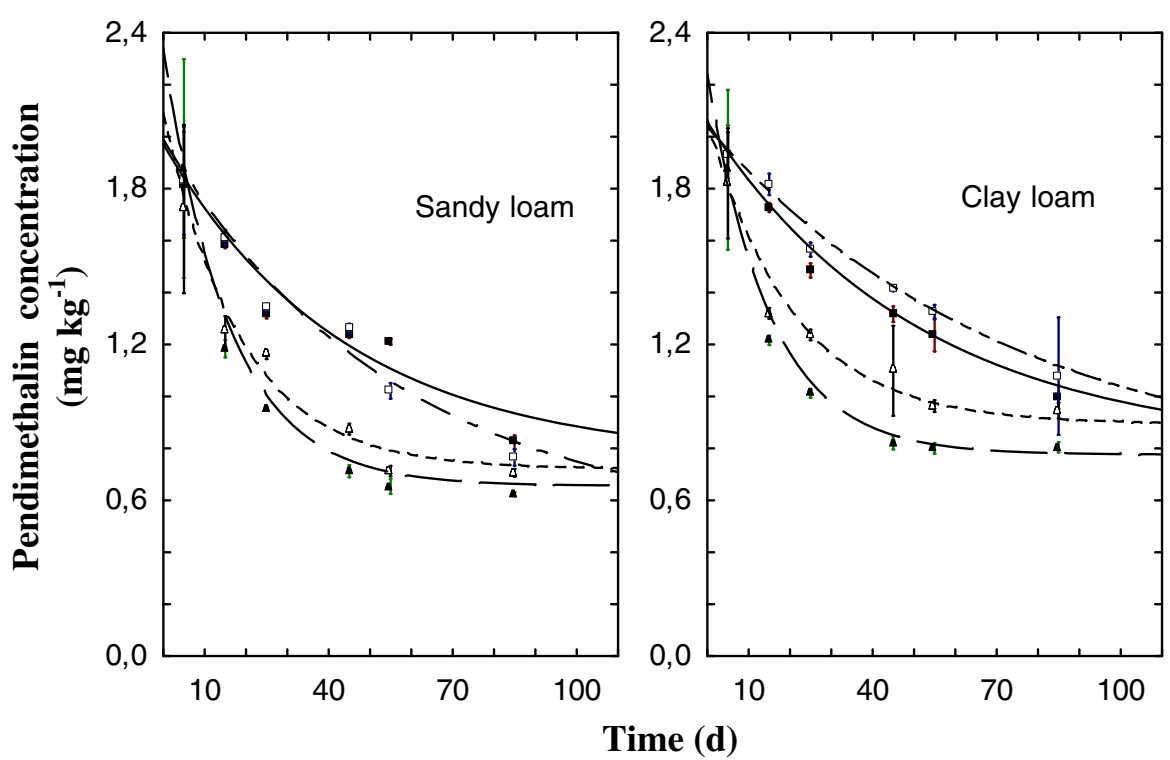

(Stranberg and Scott-Fordsmand 2004; Kulshrestha and Singh 1992). Zimdahl et al. (1984; 1994) suggested that soil type may have less influence than temperature and soil moisture. It was the reason why in the second part of study, PDM dissipation in two soils under three moisture levels and three mixtures of pesticides was performed. Results showed that increasing the moisture level in soil from $30 \%$ to $90 \%$ of field capacity could result in an almost fourfold increase of degradation rate of PDM alone in sandy loam and clay loam (Table 2). It confirmed early studies of Walker and Bond (1977), Kulshrestha and Singh (1992), Savage (1978) that persistence of several dinitroaniline herbicides was affected by soil moisture. Combinations with thiametoxam and mancozeb showed the same correlation only in sandy loam soil. Persistence of PDM was almost doubled under $60 \%$ of field capacity in sandy loam soil. Combination with mancozeb and thiametoxam influenced on the PDM more prominently under $90 \%$ than at $60 \%$ of field capacity in clay loam soil. Figure 2 showed comparison of dissipation of PDM alone and in the presence of mancozeb in two soils under two extreme moisture levels (30\% and $90 \%$ f.c.). In this case, the PDM was more persistenct in clay loam than sandy loam soil and the presence of mancozeb
Table 3 A comparison of pendimethalin constant rates, half-life, correlation coefficients in the presence of other pesticides in two soils under $60 \%$ of field capacity derived from the first-order kinetic and differential model

$P$ pendimethalin alone, $P+$ $T$ pendimethalin + thiamethoxam, $P+M$ pendimethalin + metribuzin, $P+D$ pendimethalin + mancozeb, $P+T+D$ pendimethalin + thiametoxam + mancozeb, $s l$ sandy loam, $\mathrm{cl}$ clay loam

\begin{tabular}{|c|c|c|c|c|c|c|c|}
\hline \multirow[t]{3}{*}{ Treatment } & \multirow[t]{3}{*}{ Type of soil } & \multicolumn{6}{|c|}{ Parameters of kinetics } \\
\hline & & \multicolumn{3}{|c|}{ First-order kinetics } & \multicolumn{3}{|c|}{ Differential model } \\
\hline & & $k \pm \mathrm{SE} \times 10^{-3}$ & $\mathrm{DT}_{50}$ & $R^{2}$ & $k \pm \mathrm{SE} \times 10^{-3}$ & $\mathrm{DT}_{50}$ & $R^{2}$ \\
\hline $\mathrm{P}$ & sl & $16.7 \pm 1.5$ & 41.6 & 0.9467 & $48.7 \pm 3.2$ & 26.9 & 0.9948 \\
\hline $\mathrm{P}+\mathrm{T}$ & sl & $15.7 \pm 0.9$ & 44.2 & 0.9786 & $32.7 \pm 2.4$ & 35.6 & 0.9956 \\
\hline $\mathrm{P}+\mathrm{M}$ & sl & $17.2 \pm 1.3$ & 40.3 & 0.9649 & $42.2 \pm 2.0$ & 28.7 & 0.9975 \\
\hline $\mathrm{P}+\mathrm{D}$ & sl & $11.3 \pm 1.0$ & 61.0 & 0.9445 & $41.3 \pm 3.0$ & 46.1 & 0.9945 \\
\hline $\mathrm{P}+\mathrm{T}+\mathrm{D}$ & sl & $10.1 \pm 0.6$ & 68.7 & 0.9684 & $32.2 \pm 1.9$ & 62.2 & 0.9972 \\
\hline $\mathrm{P}$ & $\mathrm{cl}$ & $11.1 \pm 1.0$ & 62.2 & 0.9382 & $46.4 \pm 2.3$ & 44.4 & 0.9972 \\
\hline $\mathrm{P}+\mathrm{T}$ & $\mathrm{cl}$ & $10.9 \pm 0.7$ & 62.2 & 0.9699 & $31.9 \pm 2.4$ & 54.4 & 0.9955 \\
\hline $\mathrm{P}+\mathrm{M}$ & $\mathrm{cl}$ & $12.8 \pm 1.1$ & 54.0 & 0.9469 & $43.8 \pm 2.4$ & 37.7 & 9.9965 \\
\hline $\mathrm{P}+\mathrm{D}$ & $\mathrm{cl}$ & $9.0 \pm 0.6$ & 69.6 & 0.9709 & $37.0 \pm 1.7$ & 63.9 & 0.9977 \\
\hline $\mathrm{P}+\mathrm{T}+\mathrm{D}$ & $\mathrm{cl}$ & $10.0 \pm 0.6$ & 69.2 & 0.9698 & $31.7 \pm 1.6$ & 63.3 & 0.9979 \\
\hline
\end{tabular}


influenced on herbicide, too. This study indicated that effect of soil moisture on dissipation and adsorption of xenobiotics mixture can be different depending on the kind of soil.

\section{Comparison of models}

Several mathematical equations have been used to describe pendimethalin (PDM) degradation in soil (Lee et al. 2000). In this study, using bi-phasic degradation was not adequate. A bi-exponential equation was superior for describing PDM dissipation in the field studied by Zimdahl et al. (1994). To illustrate different ways of quantifying PDM degradation rates in soil, Eq. 1.2 was used and a comparison to simple first-order model was applied. The simple first-order model was empirically fitting to data and $R^{2}$ from 0.938 to 0.979 was obtained. The linear regression analysis of concentration of PDM against time of incubation was statistically significant $(P<0.05)$ for each treatment, and the calculated halflives are shown in Table 3. The half-life values of PDM alone were ranged from 42 to 62 days depending on the type of soil. The first-order model however, commonly underestimates the initial rate and overestimates the final rate. It was the reason for using modification of the first-order reaction as a new differential model (Eq. 1.1). The constant rates of PDM in soil from $32 \cdot 10^{-3}$ to $49 \cdot 10^{-3}$ day $^{-1}$ and $R^{2}$ from 0.994 to 0.998 were obtained (Table 3). Prediction of pesticide concentration in soil is a significant part of the data package submitted for pesticide registration (Beulke and Brown 2001). The equation chosen to describe dissipation determines whether or not the presence of xenobiotic residues in soil may influence the value of PDM residues as compared in this study. The results of these experiments also indicate that soil properties and climatic factors are much more important than the presence of xenobiotic residues in soil. The differential model may be useful for simple and fast adjusting of data to a mathematical equation.

Crop protection products are commonly applied as formulations where the active ingredient can be present at higher concentration. Inert ingredients can be solvents, carriers, surfactants, synergists, polymers, UV absorbers, dyes, and others, which are added in various amounts. Further studies of the persistence of crop protection agent combinations in soil may provide insight into the mechanism of degradation of other herbicides and may suggest other ways in which formulations may be modified to control rates of loss.

Open Access This article is distributed under the terms of the Creative Commons Attribution Noncommercial License which permits any noncommercial use, distribution, and reproduction in any medium, provided the original author(s) and source are credited.

\section{References}

Beulke, S., \& Brown, C. D. (2001). Evaluation of methods to derive pesticide degradation parameters for regulatory modeling. Biology and Fertility Soils, 33(6), 558-564.

Chopra, I., Kumari, B., \& Sharma, S. K. (2010). Evaluation of leaching behavior of pendimethalin in sandy loam soil. Environmental Monitoring and Assessment, 160, 123-126.

FOCUS (2006). Guidance document on estimating persistence and degradation kinetics from environmental fate studies on pesticides in EU registration. Report of the FOCUS Work Group on Degradation Kinetics, EC Document Reference Sanco/10058/2005, Version 1.0. European Commission, Brussels

Fogg, P., Alistair, B. A., Boxall, A. B. A., \& Walker, A. (2003). Degradation of pesticides in biobeds: The effect of concentration and pesticide mixtures. Journal of Agriculture and Food Chemistry, 51(18), 5344-5349.

Gupta, S., Gajbhiye, V. T., \& Gupta, R. K. (2008). Soil dissipation and leaching behavior of a neonicotinoid insecticide thiamethoxam. Bulletin of Environmental Contamination and Toxicology, 80(5), 431-437.

Hanumantharaju, T. H., \& Awasthi, M. D. (2004). Persistence and degradation of metalaxyl, mancozeb fungicides and its metabolite ethylenethiourea in soils. Indian Journal of Environmental Health, 46, 312-231.

Hurle, K., \& Walker, A. (1980). Persistence and its prediction. In R. J. Hance (Ed.), Interactions Between Herbicides and the Soil (pp. 83-122). Academic Press: London.

Jaźwa, A., Szpyrka, E., \& Sadło, S. (2009). Disappearance of pendimethalin in soil and its residue in ripe fennel. Journal of Central European Agriculture, 10(2), 153-158.

Karmakar, R., Singh, S. B., \& Kulshrestha, G. (2006). Persistence and transformation of thiamethoxam, a neonicotinoid insecticide, in soil of different agroclimatic zones of India. Bulletin of Environmental Contamination and Toxicology, 76, 400-406.

Kaufman, D. D. (1966). Microbial degradation of herbicide combinations: Amitrole and Dalapon. Weeds, 14, 130-134.

Kaufman DD, Edwards DF (1982) Pesticide/microbe interaction effects on persistence of pesticides in soil. In 5 th Proceedings International Congress Pesticide Chemistry. Kyoto, Japan, 4, (pp.177-182)

Kulshrestha, G., \& Singh, S. B. (1992). Influence of soil moisture and microbial activity on pendimethalin degra- 
dation. Bulletin of Environmental Contamination and Toxicology, 48, 269-274.

Leake, C. R., Humphreys, S. P., \& Austin, D. J. (1995). Factors influencing the modeling of pesticide degradation in soil and the estimation of half-life $\left(\mathrm{DT}_{50}\right)$ and $\mathrm{DT}_{90}$ values. In A. Walker et al. (Eds.), British Crop Protection Council Monograph, 62 (pp. 217-222). Surrey, UK: Farnham.

Lee, Y. D., Kim, H. J., Chung, J. B., \& Jeong, B. R. (2000). Loss of pendimethalin in runoff and leaching from turfgrass land under simulated rainfall. Journal of Agriculture and Food Chemistry, 48, 5376-5382.

Locke, M. A., \& Harper, S. S. (1991). Metribuzin degradation in soil: I. Effects of soybean residue amendment, metribuzin level, and soil depth. Pesticide Science, 31, 221-237.

Plieth, H. E., \& Börner, H. (1985). Degradation of pendimethalin in soil of barley crop under the influence of other pesticides and straw. Zeitschrift für Pflanzenkrankheiten und Pflzenschutz, 92(3), 288-304.

Rhodes, R. C. (1977). Studies with manganese $\left[{ }^{14}\right.$ C]ethylenebis(dithiocarbamate) $\left(\left[{ }^{14} \mathrm{C}\right] \mathrm{maneb}\right)$ fungicide and $\left[{ }^{14} \mathrm{C}\right]$ ethylenethiourea $\left(\left[{ }^{14} \mathrm{C}\right] \mathrm{ETU}\right)$ in plants, soil and water. Journal of Agriculture and Food Chemistry, 25, 528-533.

Roca, E., D'Errico, E., Izzo, A., Strumia, S., Esposito, A., \& Fiorentino, A. (2009). In vitro saprotrophic basidiomycetes tolerance to pendimethalin. International Biodeterioration and Biodegradation, 63, 182-186.

Savage, K. E. (1978). Persistence of several dinitroaniline herbicides as affected by soil moisture. Weed Science, 26, 465-471.

Singh, B. K., Walker, A., \& Wright, D. J. (2002a). Degradation of chlorpyrifos, fenamiphos, chlorothalonil alone and in combination and their effect on soil microbial activity. Environmental Toxicology and Chemistry, 21, 2600-2605.

Singh, B. K., Walker, A., \& Wright, D. J. (2002b). Persistence of chlorpyrifos, fenamiphos, chlorothalonil, and pendimethalin in soil and their effects on soil microbial characteristics. Bulletin of Environmental Contamination and Toxicology, 69, 181-188.

Smith, A. E. (1979). Soil persistence experiments with [14 C] 2,4-D in herbicidal mixtures, and field persistence studies with tri-allate and trifluralin both singly and combined. Weed Research, 19, 165-170.

Smith, A. E. (1982). Herbicides and the soil environment in Canada. Canadian Journal of Soil Science, 62(3), 433-460.

Smith, R. H., Oliver, J. E., \& Lusby, W. R. (1997). Degradation of pendimethalin and its $\mathrm{N}$-nitroso and $\mathrm{N}$-nitro derivatives in anaerobic soil. Chemosphere, 8, 855-867.

Stranberg, M., \& Scott-Fordsmand, J. J. (2004). Effects of pendimethalin at lower tropic levels - a review. Ecotoxicology Envronment Safety, 57, 190-201.

Swarcewicz, M. (2002). Study on the persistence of herbicides in the presence of other xenobiotics in soil. Akademia Rolnicza Szczecin Rozprawy, 208, 28-53.

Swarcewicz, M., Jurgiel-Małecka, G., \& Włodarczyk, M. (2003). Influence of some fungicides on respiration and nitrification in the soil. Progress in Plant Protection, 43(2), 181-184.

Tsiropoulos, N. G., \& Miliadis, G. E. (1998). Field persistence studies on pendimethalin residues in onions and soil after herbicide postemergence application in onion cultivation. Journal of Agriculture and Food Chemistry, 46, 291-295.

Walker, A., \& Bond, W. (1977). Persistence of the herbicide AC 92,553, N-(1-ethylpropyl)-2,6-dinitro-3,4-xylidine, in soil. Pesticide Science, 8, 359-365.

Wauchope, R. D., Buttler, T. M., Hornsby, A. G., AugustijnBeckers, P. W. M., \& Burt, J. P. (1992). Pesticide properties database for environmental decision making. Review of Environmental Contamination Toxicology, 123, 1-157.

Weber, J. B. (1990). Behaviour of dinitroaniline herbicides in soils. Weed Technology, 4, 394-406.

Wybieralski, J., Swarcewicz, M., \& Osumek, R. (2000). Side effects of pesticides on respiration and nitrification processes in soil. Zeszyty Problemowe Postepow Nauk Rolniczych, 472, 725-730.

Zimdahl, R. L., \& Gwynn, S. M. (1977). Soil degradation of three dinitroanilines. Weed Sci, 25, 247-251.

Zimdahl, R. L., Catizone, P., \& Butcher, A. C. (1984). Degradation of pendimethalin in soil. Weed Science, 32, 408-412.

Zimdahl, R. L., Cranmer, B. K., \& Stroup, W. W. (1994). Use of empirical equations to describe dissipation of metribuzin and pendimethalin. Weed Science, 42, 241-248. 